\title{
Integrando metodologias na análise de dados sob o paradigma interacionista simbólico: um caso prático
}

\author{
Integrating methodologies in the data analysis under the symbolic interacionist paradigm: a \\ practical example
}

Lilian Aparecida Pasquini Miguel ${ }^{1}$

Silvio Popadiuk ${ }^{2}$

\section{Resumo}

Este artigo aborda o desafio na combinação de diferentes métodos de análise, por conta da diversidade de dados coletados no campo, de forma que tal diversidade de métodos não apresente conflitos epistemológicos. É oferecido o relato de um caso prático, cujo objeto de investigação era o entendimento sobre como o compartilhamento do conhecimento tácito ocorre tendo os signos como mediadores, analisados à luz da semiótica. Detalha os diferentes tipos de dados coletados e explica como essa diversidade foi tratada pela combinação de diferentes métodos, alinhados entre si, dentro do paradigma interpretacionista simbólico. Espera-se que este trabalho contribua como exemplo para trabalhos com propostas semelhantes.

Palavras-chave: Semiótica. Interacionismo simbólico. Grounded theory.

\begin{abstract}
This article discusses the challenge in combining different methods of analysis, due to the diversity of data collected in the field, so that such a diversity of methods does not present epistemological conflicts. It is offered an account of a case study, whose object of research was the understanding of how the sharing of tacit knowledge occurs with signs as mediators, analyzed in the light of semiotics. This study details the different types of data collected, and explains how this diversity was treated by a combination of different methods, aligned with each other within the symbolic interpretationist paradigm. It is expected that this work contributes as a practical example to researchers with similar proposals.
\end{abstract}

Keywords: Semiotics. Symbolic interactionism. Grounded theory.

Artigo submetido em 5 de julho de 2013 e aceito para publicação em 19 de fevereiro de 2014.

DOI: http://dx.doi.org/10.1590/1679-39519359

1 Professora Assistente, dos cursos de Graduação e de Pós Graduação - Lato Sensu, em Administração de Empresas, da Universidade Presbiteriana Mackenzie; Doutora em Administração de Empresas pela Universidade Presbiteriana Mackenzie. Endereço: Rua da Consolação, 896 - Prédio 45 - Consolação, CEP 01302-907, São Paulo - SP, Brasil. E-mail: lilian.miguel@mackenzie.br

2 Professor Adjunto do Programa de Pós Graduação em Administração de Empresas da Universidade Presbiteriana Mackenzie; Doutor em Administração pela FEA-USP. Endereço: Rua da Consolação, 896 - Prédio 45 - Consolação, CEP 01302-907, São Paulo - SP, Brasil. E-mail: spopadiuk@mackenzie.br 


\section{Introdução}

O trabalho de pesquisa demanda, por vezes, a adoção de técnicas de análise de dados complementares à técnica de pesquisa. A fase de análise de dados é crítica, exigindo muito cuidado (CAMPOS, 2004). O autor enfatiza que a adoção do método de análise "deve obrigatoriamente proporcionar um olhar multifacetado sobre a totalidade dos dados recolhidos no período de coleta" (p. 611), em função da diversidade de significados que os dados acabam por produzir.

Não obstante, a escolha do método de análise deve-se alinhar com o paradigma predominante no trabalho científico, de forma a produzir resultados que se coadunem com a riqueza de significados existentes nas informações colhidas no campo. Essa mesma riqueza, pode, no entanto, demandar a combinação de técnicas de análise, de forma que todo tipo de dado possível faça parte do estudo e seus significados possam ser devidamente capturados pelo pesquisador, visando a melhor compreensão do fenômeno em análise.

Com este artigo, visa-se apresentar o relato de um caso prático em que a combinação de técnicas de análise dos dados colhidos durante o processo de elaboração da tese de doutorado pode contemplar não somente a diversidade dos dados colhidos, mas, principalmente a riqueza de significados que tais dados continham, dentro do paradigma interacionista simbólico.

São apresentados aqui os aportes teóricos relacionados aos métodos de análise utilizados, assim como o processo adotado em todo o percurso da análise de dados. Destaca-se, entretanto, que o foco do artigo situase na técnica de coleta e, principalmente, na análise dos dados. Portanto, os resultados, em si, da pesquisa não são objeto de considerações em termos de conclusões, recomendações e implicações práticas ou teóricas. Assim, avalia-se que a sua maior contribuição consiste no relato das etapas de coleta e das técnicas de análise, que envolveram os conceitos inerentes ao interacionismo simbólico.

Pela revisão da literatura ao elaborar a tese objeto deste artigo, identificou-se que a abordagem aqui apresentada para a coleta e a análise dos dados era pouco usual, devido à necessidade do pesquisador possuir um forte arcabouço teórico sobre as técnicas apresentadas. Por essa razão, esse artigo tem potencial para produzir insigths em outros pesquisadores interessados em realizar estudos de caso complexos que envolvam uma grande quantidade de dados derivados de várias fontes, permitindo que suas triangulações sejam mais bem fundamentadas e consistentes.

Devido à impossibilidade de apresentar neste artigo mais detalhes sobre as especificidades da coleta e das análises, o leitor poderá acessar o documento original dessa pesquisa mediante solicitação ao autor ou pelo acesso ao site da página da universidade criado para as divulgações dos trabalhos de seus pesquisadores.

\section{A escolha metodológica}

A adoção do processo metodológico que desse conta do objetivo geral do trabalho de pesquisa, que tinha como problema de pesquisa investigar como o compartilhamento do conhecimento tácito era mediado pela semiótica, em uma organização cooperativa produtora de forjados a frio, baseou-se nestas premissas:

- O problema de pesquisa segue um paradigma interacionista simbólico;

- Os dados dizem respeito exclusivamente à visão do grupo de indivíduos com o qual o pesquisador interagiu durante o processo de pesquisa, portanto, contextual;

- A característica desses dados é, por natureza, subjetiva. Portanto, o processo de análise depende da interpretação do pesquisador; 
- O tema de pesquisa envolve aspectos de difícil observação, demandando dados de diversos tipos, para que o fenômeno fosse mapeado.

Tendo isso em mente, o desenho deste estudo delineou-se seguindo o caminho sobre o qual passamos a discorrer.

\section{A estratégia adotada}

Uma vez que se trata de uma pesquisa cujos aportes teóricos de base, embora forneçam um conteúdo intenso de informação, não mostram o enlace teórico como considerado no problema de pesquisa, adotou-se a estratégia de estudo de caso.

Embora haja certa diversidade na definição do que seja um estudo de caso, reforçada pela utilização dessa estratégia em várias áreas do conhecimento, como informa Godoy (2006), entre as várias abordagens existentes, optou-se pela abordagem sugerida por Merriam (1988), cuja vertente construtivista em educação parecia adequar-se à linha seguida no estudo, principalmente pela visão holística defendida pela autora.

A ideia de que um estudo de caso não se refere a apenas um método parece ser comum nas várias definições sobre o conceito que define essa estratégia, mas, como explica Godoy (2006), relaciona-se "fundamentalmente, à escolha de um determinado objeto a ser estudado" (p. 119).

Na edição de 1998 de seu livro, Merriam assume uma evolução em seu pensamento quanto ao que venha a ser um estudo de caso, definido 10 anos antes por ela como um "(...) intensive, holistic description and analysis of a single instance, phenomenon, of social unit” (MERRIAM, 1988, p. 21), afirmando que depois de 10 anos de experiência de campo, ela conclui que a essência de um estudo de caso é a delimitação do fenômeno estudado, considerado por ela, como o verdadeiro caso - seja uma pessoa, um grupo de pessoas, seja uma comunidade (MIGUEL, 2010).

É possível que, para Merriam (1998), isso pareça ser mais do que um aspecto semântico ou processual. A autora apoia nessa ideia, todo o aspecto estratégico, tático e operacional do desenho da pesquisa, uma vez que da delimitação do fenômeno sob investigação decorrerem a natureza dos dados a serem buscados, a natureza teórica a ser previamente levantada, a definição do esgotamento da pesquisa de campo, o método de análise a ser utilizado, o tipo de caso a ser estudado.

A importância na escolha do caso encontra-se no fato de ser ele uma ilustração daquilo que se pretende pesquisar, ou ainda, algo "intrinsically interesting" (p. 28) dentro de uma linha de estudo. De qualquer forma, o caso é considerado um sistema delimitado (MERRIAM, 1998).

Não obstante, Merriam (1998) enfatiza que os estudos de caso são direcionados à busca pela compreensão dos processos sociais envolvidos no contexto estudado - "o caso, o que ocorre por meio de uma análise, holística e intensa, baseado em diversas fontes de dados" (p. 16).

Acredita-se, no entanto, que a melhor justificativa para a adoção dessa estratégia na pesquisa em questão encontra-se na ideia de que, segundo essa autora, os estudos de caso referem-se a problemas de pesquisa orientados pela busca de "insights, discovery and interpretation rather than hypothesis testing" (p. 29), principalmente, dentro de um escopo contextual (MERRIAM, 1998).

Além disto, pode-se depreender que o caso único, objeto deste estudo, além do que Merriam (1998, p.28) classifica como "intrinsically interesting", pode, também, ser classificado como o que a autora denomina 
como heurístico (investigativo), pois busca lançar luz ao entendimento da forma como um fenômeno ocorre, avaliando-o de forma a potencializar sua aplicabilidade.

O caso desta pesquisa restringe seu foco ao que pode ser considerado um processo: o compartilhamento de conhecimento tácito entre os membros da organização Fênix, tendo os signos como mediadores. Entretanto, esse processo é, em si mesmo, algo amplo, que não pode ser restringido a menos do que é, sem o risco de se perderem informações preciosas sobre o fenômeno.

Esse aspecto ilustra bem o que Merriam (1988) afirma a respeito das habilidades necessárias ao pesquisador que adota essa estratégia, uma vez que "a pesquisa do tipo estudo de caso coloca o investigador num grande oceano não mapeado" (p. 37).

Portanto, o que está dentro dessa delimitação, ou seja, o caso, diz respeito, exclusivamente, ao compartilhamento do conhecimento tácito, enquanto processo, em suas diferentes nuances e seus diferentes tipos de interação - seja entre os indivíduos, seja entre os subgrupos da Fênix, envolvendo o entendimento sobre os aspectos correlatos a esse processo, quais sejam: história da empresa, que busca o entendimento sobre os aspectos relacionados às interações entre seus membros e grupos, formas e características do compartilhamento do conhecimento, tipos de conhecimento e signos, que permeiam a organização, ou seja, elementos que se constituem nos objetivos específicos definidos no capítulo anterior.

Esses aspectos alinham-se, em propósito e método, ao que Merriam (2002) afirma ser a chave para o entendimento dos estudos qualitativos, nas palavras da autora: "meaning is socially constructed by individuals in interaction with their world" (p. 3), considerando que o significado varia conforme a interpretação sobre a construção da realidade no contexto em que ocorre, razão pela qual se classifica este estudo de caso como o que Merriam (1988) define como interpretativo, uma vez que inspirados no protocolo da grounded theory (GT), buscou-se encontrar padrões que levassem a categorias conceituais, que permitissem a compreensão buscada. Contudo, a despeito da utilização da $G T$, como explicado mais adiante, a construção de uma teoria substantiva não fazia parte originalmente dos objetivos do trabalho de pesquisa em questão (MIGUEL, 2013).

Ainda segundo a autora, para o esforço de coleta e interpretação dos dados, foi utilizada uma combinação de técnicas, cujos protocolos e abordagens são considerados alinhados em termos epistemológicos e cujos procedimentos são flexíveis o bastante para a criação de um inter-relacionamento entre eles, o que se adéqua à linha qualitativa de estudo de caso de Merriam (1998), que não opõe restrições a técnicas de coleta ou análise.

Pode-se inferir, portanto, que tais postulados derrubem a ideia, defendida por alguns autores, de que os estudos de caso sejam apenas uma das formas de coleta de dados. São, portanto, mais uma estratégia de pesquisa, que contribui para a maneira de lançar o olhar sobre um determinado fenômeno.

\section{As muitas formas na coleta de dados}

A coleta de dados do estudo objetivo deste artigo envolveu, como sujeitos da pesquisa, os membros da Fênix, em quaisquer áreas de atuação.

Salienta-se que, não obstante esta pesquisa tenha como unidade de análise interações que possibilitem o compartilhamento do conhecimento, a investigação foi conduzida com os indivíduos e com os grupos, formais ou informais, em momentos diferentes, pois o que se buscou observar relaciona-se com a interação e não com o indivíduo/grupo em si, o que torna, segundo Bandeira-de-Mello e Cunha (2006), a quantidade de interações mais relevante que a quantidade de sujeitos. 
Como já mencionado, o escopo do caso demandou que os dados fossem obtidos de várias formas e formatos, o que gerou a necessidade do domínio de novos processos e instrumentos de coleta, tais como equipamentos de vídeo e foto, assim como aplicativos de edição desses conteúdos.

A coleta de dados se deu de várias formas: por meio de entrevistas, observações participativas e documentos fornecidos pela direção da Fênix, processo este totalmente aprovado previamente por seus diretores, assim como pelos indivíduos entrevistados, que receberam pouco antes da entrevista um documento assinado pelo pesquisador, comprometendo-se eticamente com a utilização dos conteúdos relatados por esses entrevistados, assim como com os conteúdos observados pelo próprio pesquisador.

As entrevistas, em um total de seis, culminando em um total de oito eventos, pela necessidade de aprofundamento posterior com dois entrevistados, foram realizadas com membros da Fênix, escolhidos por julgamento, cujas funções dentro da empresa vão desde o nível mais operacional (duas), passando por funções administrativas (duas), até as funções executivas (duas).

Gaskell (2008) afirma que as entrevistas individuais dizem respeito à busca pelo entendimento mais profundo sobre o mundo do entrevistado, enquanto as entrevistas em grupos estão mais relacionadas à busca pela compreensão de linguagens e comportamentos locais.

Uma vez que, para conhecer a história da Fênix, seria preciso conhecer a história de seus membros, e na impossibilidade de entrevistar todos os 108 profissionais da organização, entre cooperados e funcionários, optou-se por escolher por julgamento aqueles que, pelas observações, corroboradas principalmente pelo diretor financeiro da empresa, mostraram-se como representantes dos grupos informais existentes: a diretoria, o "chão de fábrica" e o nível intermediário.

Localizada no interior de São Paulo, a Fênix renasceu em uma nova configuração estatutária - cooperativa das cinzas de uma empresa metalúrgica falida, a ponto de não reunir condições para pagar seus empregados, segundo relatos deles. Assim, os antigos empregados resolveram assumir a empresa e criaram-na como uma cooperativa. Hoje, anos depois dessa decisão, a empresa possui, além dos cooperados, alguns funcionários contratados pelo regime da legislação trabalhista (MIGUEL, 2013).

É importante lembrar que as entrevistas podem ser consideradas mais como relatos, uma vez que foram conduzidas de forma aberta e durante as quais, coube ao pesquisador o papel de instigador das narrativas a respeito dos temas de interesse da pesquisa, trazendo à luz detalhes, impressões e reflexões direcionadas ao fenômeno objeto do estudo.

Tais relatos foram gravados com a permissão prévia dos entrevistados e, em seguida, transcritos in totum, o que considerou o cuidado de que fosse transferida, para a forma textual, toda e qualquer manifestação verbal de pensamento, parecesse ela relevante ou não, naquele momento, gerando um total de 236 páginas de transcrição para possibilitar o processo de codificação. Esse número inclui a validação das primeiras análises, feita com o diretor presidente e com diretor financeiro da Fênix, mas não inclui as observações participativas, também transcritas.

Analisando a utilidade dos dados visuais em pesquisas sociais, Loizos (2008) defende sua aplicação, enfatizando o poder que uma imagem possui em relação ao "registro de ações temporais e dos acontecimentos reais - concretos, materiais" (p. 137), não importando se imagens paradas ou em movimento. $\mathrm{O}$ autor afirma que a natureza dos dados deve seguir a natureza da investigação, sem contar que o impacto visual tem mostrado apelo crescente, na atualidade.

Um elemento fundamental a ser considerado aqui é que, segundo Loizos (2008), o olhar do intérprete das imagens visuais é direcionado pelo olhar de quem as elabora. No caso do estudo em questão, as duas figuras se fundem no seu pesquisador. Portanto, o objetivo foi tão somente registrar os conteúdos considerados importantes para a pesquisa e, ao coletá-los, já eram interpretados, fazendo desses registros uma forma de 
"prova" dos achados imediatos, dentro da Fênix, ao longo do processo de pesquisa, orientados pelos aportes teóricos de base.

Todas as imagens seguiram apenas uma das quatro formas possíveis elencadas por Loizos (2008): "os sujeitos foram pegos de surpresa pelo fotógrafo, comportando-se de maneira informal" (p. 145). A isto, é preciso acrescentar que o comportamento de todas as pessoas que aparecem nas imagens produzidas pelo pesquisador foi considerado natural, uma vez que não houve uma combinação anterior a respeito do conteúdo das imagens que seriam colhidas, ou seja, a câmera do pesquisador parece não ter influenciado os protagonistas mais nem menos que o gravador dos relatos colhidos durante as entrevistas ou o caderno de notas, durante as observações participativas.

Tendo em conta a natureza do compartilhamento do conhecimento tácito, em que as palavras não o esboçam, e é na prática diária que é manifestado, optou-se por observar os comportamentos envolvidos no processo de compartilhamento por meio de observações participativas. Assim, três eventos distintos em seus conteúdos e participantes foram feitos em momentos previamente combinados com o corpo diretivo da empresa (MIGUEL, 2010).

O primeiro, quando foi permitido ao pesquisador presenciar uma reunião operacional, com um grupo envolvendo profissionais das áreas de manufatura, qualidade, compras e planejamento de produção, num total de sete pessoas, cujo registro foi feito com base em anotações in loco durante e logo depois da reunião.

No segundo, o pesquisador pôde presenciar uma assembleia do grupo de cooperados, reunião com cerca de duas horas de duração, cujo registro baseou-se em anotações in loco, uma vez que a gravação em áudio não foi permitida, além de algumas fotos feitas em determinados momentos, escolhidas como significativas.

A diretoria da Fênix permitiu que se registrasse em vídeo toda a empresa em vários momentos do processo produtivo, assim como em outros momentos do processo de gestão, além de poder fazer registros por meio de fotos. A coleta de dados por meio de imagens paradas e em movimento propiciou o registro de momentos cuja interpretação, à luz das abordagens teóricas envolvidas na pesquisa, possibilitou o atingimento dos objetivos específicos do trabalho em questão.

Documentos fornecidos pela diretoria da empresa contendo informações a respeito da história da empresa, organização funcional e perfil demográfico de seus membros - cooperados e funcionários contratados, dando conta de seu grau de instrução, idade, área de atuação dentro da empresa, e organograma funcional, basicamente - foram fornecidos pela diretoria da empresa, tão logo solicitados pelo pesquisador.

\section{A articulação da análise de dados}

A análise dos dados coletados demandou, por parte do pesquisador, um aprendizado infinitamente maior e mais complexo do que já havia sido demandado no esforço de coleta desses dados, uma vez que, dada a diversidade dos dados coletados, foi necessário que se lançasse mão da articulação de alguns métodos e técnicas de análise para que pudesse dar conta de criar uma interpretação consistente, tecnicamente e epistemologicamente falando.

Em função disso, diferentes dados foram analisados sob a ótica de diferentes métodos, técnicas e autores, complementares e não conflitantes entre si, quanto ao método e à epistemologia, em função de estarem ligados ao paradigma interacionista simbólico.

Não obstante, por conta da utilização da análise semiótica como um desses métodos, foi necessário que, durante o processo de análise e interpretação, alguns aportes teóricos fossem agregados, para explicar o simbolismo do aspecto analisado, em seus significados intrínsecos. 
Tais aportes, entretanto, embora contribuíssem de forma substantiva para a elucidação dos significados, resultaram das escolhas feitas pelo pesquisador sobre eles, embasadas em suas interpretações, ajudando-o a explicar a realidade analisada sob sua ótica, exclusivamente, o que faz dessa realidade algo consideravelmente contextual.

Visando facilitar o entendimento dessa articulação por parte do leitor, o processo de análise com base no tipo de dado a que se relaciona é descrito a seguir.

\section{Análise dos relatos e das observações}

A análise dos dados obtidos por meios dos relatos e das observações, visando a identificação dos primeiros conteúdos sígnicos, à luz da taxonomia semiótica peirceana (PEIRCE [1931-1958], 2000), e dos elementos relacionados ao conhecimento tácito (POLANYI, 1962; 1966), envolveu a adoção do protocolo metodológico baseado na abordagem construtivista da Teoria Fundamentada nos Dados (Grounded Theory $(G T)$, denominação mais popular academicamente), na linha oferecida por Charmaz (2006).

A GT criada por Glaser e Strauss (1967) tem sua origem no Interacionismo Simbólico (GOULDING, 2002). Entretanto, a partir de um dado momento, esses autores seguiram por caminhos distintos dentro do método. Glaser adotou uma abordagem considerada mais aberta, enquanto Strauss assumiu uma abordagem considerada mais estruturada.

Como solução intermediária, adotou-se a visão construtivista de $G T$ sugerida por Charmaz (2006), cuja proposta situada entre os extremos trilhados por seus autores originais, obteve a aprovação tanto de Glaser quanto de Strauss. A adoção de Charmaz (2006) justifica-se não só pela abordagem construtivista, mas também pelo fato de sua metodologia possuir a flexibilidade proposta por Glaser e uma estruturação de processo mínima, sugerida por Strauss, sem perder suas características paradigmáticas originais.

A escolha da teoria fundamentada como método de análise está respaldada em dois pontos principais: (1) o estudo em questão segue uma linha interpretativista, cuja análise possui um escopo subjetivista e contextual; (2) este escopo decorre da semiótica tanto como conteúdo teórico de base quanto como método de análise, para o qual não existe um protocolo único específico, permitindo ao pesquisador a utilização de diversas técnicas, conforme seu objetivo de pesquisa, o mesmo ocorrendo com a estratégia de estudo de caso defendida por Merriam (1998).

Segundo Bandeira-de-Mello e Cunha (2006), a $G T$ localiza-se entre os pressupostos objetivistas e subjetivistas das Ciências Sociais, tendo como foco o indivíduo como ator social, a realidade como discurso simbólico, a análise simbólica e a influência do interacionista simbólico, ou seja, a interação do homem com o mundo por meio de símbolos passíveis de interpretação.

Os códigos e categorias foram criados a posteriori, emergindo da interpretação feita com base nas falas dos entrevistados, em linha com a visão construtivista adotada neste estudo.

Embora seja um método de pesquisa, a $G T$ é também uma técnica de análise, forma em que foi utilizada no trabalho em questão, cujo objetivo não contemplava a criação de uma teoria substantiva (MIGUEL, 2010). Não obstante, procurou-se seguir o mesmo protocolo procedimental, ou seja, as teorias consideradas a priori orientam, mas não engessam a análise, sob o processo apresentado na Figura 1. 
Figura 1

\section{Método de comparações constantes}

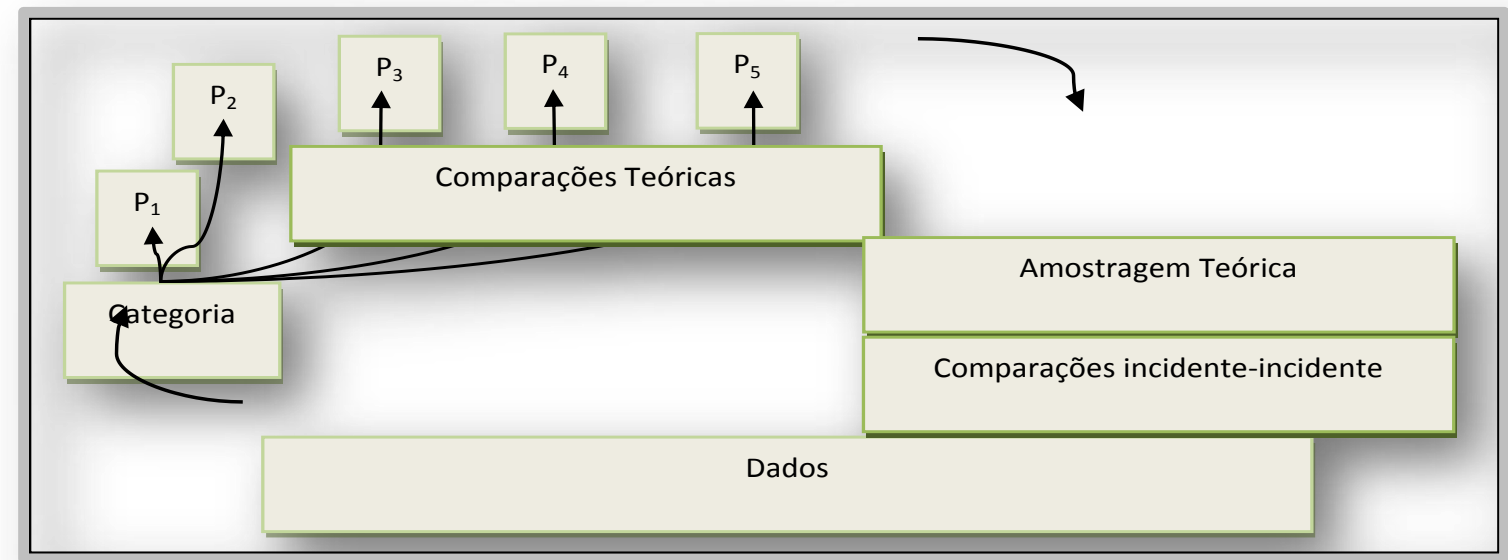

Fonte: Adaptado de Bandeira-de-Mello e Cunha (2006, p. 251)

Foi seguido, então, o roteiro de comparações constantes na busca das similaridades e das diferenças entre os dados, os incidentes e as teorias, utilizando-se a lógica abdutiva, que para Bandeira-de-Mello e Cunha (2006, p. 252), "(...), permite a descoberta (criatividade, sensibilidade teórica) e a validação das causas a partir dos efeitos (observações)".

O processo de $G T$ desenvolvido por Charmaz (2006) segue uma sequência de seis grandes passos, que são objeto de um processo de circularidade quando em elaboração, em função das comparações constantes, envolvendo: (1) coleta de dados; (2) codificação em três fases: (a) codificação inicial - são as primeiras categorias; (b) codificação focada - são as grandes categorias, nas quais as primeiras são agrupadas; (c) codificação axial - são as relações estabelecidas entre categorias e subcategorias; (d) codificação teórica formulação de hipóteses quanto às relações encontradas na codificação focada; (3) elaboração de memos (notas sobre relações, hipóteses, pré-teoria); (4) amostragem, saturação e classificação teóricas; (5) elaboração da primeira versão; e (6) reflexão sobre o processo de pesquisa: versões de contestação e revisões, comparação e interação, e avaliação.

Em função do objetivo do estudo em questão, o pesquisador inspirou-se nesses passos, criando, entretanto, uma adaptação, reduzindo seu escopo. Por isto, seguindo fielmente o primeiro passo, a codificação em suas três primeiras fases, combinando a última (codificação teórica) com o terceiro passo (elaboração de memos).

O quarto passo, entretanto, foi desconsiderado pelas razões já explicitadas. Os dois últimos passos também foram utilizados de forma adaptada ao desenho desta pesquisa. Assim, o processo final utilizado dá conta desta sequência: (1) coleta de dados; (2) codificação em três fases: (a) codificação inicial, (b) codificação focada, (c) codificação axial; (3) codificação teórica e elaboração de memos; (4) elaboração da primeira versão: utilizada para a elaboração do modelo de relações, em que são articulados os códigos axiais, incluindo toda a conexão teórica; (5) reflexão sobre o processo de pesquisa: foi elaborada de forma a dar alinhamento ao processo efetivamente conduzido e os achados, na forma em que foram analisados e interpretados - neste caso, passo destinado à análise de consistência do modelo de relações.

A seguir, de forma mais detalhada, discorre-se sobre o processo, oferecendo exemplos baseados nos dados extraídos da própria pesquisa de campo. 
- Coleta de dados: Ocorreu de forma concomitante à análise - uma vez elaborada a entrevista, a transcrição do conteúdo gravado foi analisada, de forma a gerar os primeiros códigos iniciais.

A partir da primeira, todas as entrevistas passaram pelo mesmo processo. Seus conteúdos eram divididos em unidades de significados, que eram comparadas com os códigos iniciais já existentes e incorporadas a estes, caso a similitude entre elas fosse observada. Caso contrário, novos códigos iniciais eram criados. Isto foi feito para todas as entrevistas, uma a uma, paulatinamente, para, em seguida, passar para as fases seguintes do processo de codificação, descrito a seguir.

Codificação: A codificação na linha da $G T$, de Charmaz (2006), seguiu passos que podem ser considerados mais como fases, cujos procedimentos e denominações são aqui descritos (MIGUEL, 2010).

Tendo em vista a quantidade de códigos gerados e os procedimentos metodológicos utilizados no processo de codificação, acredita-se que o critério da confiabilidade não estivesse em risco, considerando a sugestão de verificar a consistência das categorias de classificação de todos os dados coletados, como sugerem Silverman (2000; 2001) e Godoi (2006).

$\checkmark$ Codificação inicial: Refere-se, como o próprio nome diz, às primeiras categorizações, dando origem a códigos iniciais que refletem a fala do entrevistado. Essa codificação foi feita, como sugere a autora com base nas unidades de significado atribuídas como tais pelo pesquisador. Como explica Charmaz (2006), "coding means categorizing segments of data with a short name that simultaneously summarizes and accounts for each piece of data" (p. 43).

É importante salientar que essa fase inicial de codificação é o que orienta todo o processo posterior de análise, pois o que se denomina como unidades de significado e que recebe o nome de incidência por Charmaz (2006), refere-se às dimensões de pensamento dos entrevistados, manifestas em seus relatos, que se relacionam com os conteúdos teóricos que permeavam a mente do pesquisador no momento da obtenção dos dados e da análise, em si.

A incidência é o pilar da codificação na GT. Nesse método, não importa a quantidade de entrevistados, mas a quantidade de incidências (CHARMAZ, 2006). Por conta de sua importância e primando pela transparência, foi necessário dar à incidência uma denominação distinta da utilizada por Charmaz (2006), e que fazia mais sentido para o que efetivamente foi utilizado neste estudo, pois as falas dos entrevistados, analisadas em recortes pequenos, praticamente linha a linha, e denominadas pela autora como incidências, no caso deste trabalho, algumas vezes eram longos e entrecortados amontoados de palavras soltas, sem finalização, o suficiente para conter apenas uma única ideia, ou seja, uma única unidade de significado, expressa ao longo de várias linhas, como no exemplo apresentado aqui, quando o entrevistado responde ao ser questionado sobre uma das formas como compartilha seu conhecimento:

\footnotetext{
"Mas quando dá um problema na máquina, aí o que mais eu acompanho, que é o coordenador. Vou lá, eu explico pra ele: - Olha, isso aqui é assim, assim, tal. Agora, na parte da engenharia que seria a parte de desenvolvimento, então quando sai o desenvolvimento, que vem o produto, tem hora que eu rabisco, faço uns ETzinhos para parte da engenharia. Falo: - Termina isso aqui para mim” (Entrevistado E.).
}

Por isso, se o método fosse utilizado ipsis literis, seria necessário cortar em trechos sem um significado contextual maior dentro da linha que buscava entender, razão pela qual foi dada uma nova denominação exclusivamente para este estudo, visando não contaminar o método original e adequá-lo à natureza das respostas dos entrevistados. 
Na sequência, o que Charmaz (2006) chama de short name, transformou-se, no estudo em foco, em frases com uma redação, que praticamente copiam a fala do entrevistado. No Quadro 1, este procedimento é exemplificado.

É importante salientar que, nesta fase, foi feito um pequeno ajuste na forma de codificação inicial, que em absolutamente nada comprometeu o resultado final.

Em vez de dar ao código inicial uma redação mais geral, de forma que se pudesse adensá-lo com unidades de significado originadas pelas falas de outros entrevistados, escolheu-se dar-lhes uma redação mais específica à dimensão de pensamento de cada entrevistado.

\section{Quadro 1}

Unidade de significado $\rightarrow$ Código inicial

\begin{tabular}{|l|l|}
\hline \multicolumn{1}{|c|}{ Unidade de significado da fala } & \multicolumn{1}{c|}{ Código inicial } \\
\hline $\begin{array}{l}\text { "passei a acreditar que as pessoas fazem a } \\
\text { diferença" (Entrevistado M). }\end{array}$ & $\begin{array}{l}\text { Passando a acreditar que as pessoas fazem a } \\
\text { diferença. }\end{array}$ \\
\hline
\end{tabular}

Fonte: Elaborado pelos pesquisadores, com base nos dados da pesquisa de campo.

Isso fez com que os códigos iniciais recebessem menos referências (unidades de significado). Por outro lado, preferiu-se agrupar os códigos iniciais na fase de codificação focada, que, então, teve códigos focados mais densos por conta do ajuste feito.

Esse procedimento permitiu que se pudessem criar mais níveis de categorias, na fase da codificação focada, contribuindo significativamente para capturar mais especificamente as dimensões de cada uma delas.

Essa fase de análise geral originou 1.914 códigos iniciais, que, quando revisitados na circularidade criada pelo próprio método, culminaram em 2.126 códigos iniciais. Isto porque considerando que ao serem agrupados em diferentes categorias (código focado), simultaneamente, alguns códigos iniciais possuíam mais de uma dimensão de pensamento na interpretação do pesquisador, mesmo dentro da mesma unidade de significado (incidência), na fase de codificação focada.

$\checkmark$ Codificação focada: São as categorias e subcategorias que emergem do agrupamento dos códigos iniciais. Tal agrupamento é feito com base naquilo que as codificações iniciais apresentam em comum, em termos de significados, e que podem apresentar uma primeira ideia de taxonomia. Neste estudo, essas categorias e subcategorias receberam apenas um nome, significando um construto. Nesta fase, é comum que apareçam ideias que não se relacionam claramente com as teorias que orientavam o estudo inicialmente. Entretanto, é isso que dá riqueza ao trabalho, razão pela qual esses achados foram considerados por conta do valor contextual oferecido por eles ao caso pesquisado, exemplo mostrado no Quadro 2. 
Quadro 2

Códigos iniciais $\rightarrow$ Código focado

\begin{tabular}{|l|l|l|}
\hline \multirow{2}{*}{ Códigos iniciais } & \multicolumn{2}{c|}{ Código focado } \\
\cline { 2 - 3 } & Subcategoria & \multirow{2}{*}{ Categoria } \\
\hline $\begin{array}{l}\text { Acreditando que sem a prática, o conhecimento } \\
\text { teórico é incompleto. }\end{array}$ & \\
$\begin{array}{l}\text { Assumindo que os cooperados devam ser } \\
\text { encorajados a se envolver em reduções de set up. }\end{array}$ & Desempenho & \multirow{2}{*}{ Gestão } \\
\hline $\begin{array}{l}\text { Afirmando que possuem mais agilidade na decisão } \\
\text { que não há em outras empresas. } \\
\text { Afirmando que a garantia das respostas é a decisão } \\
\text { feita pelo grupo. }\end{array}$ & $\begin{array}{l}\text { Processo } \\
\text { decisório }\end{array}$ & \\
\hline
\end{tabular}

Fonte: Elaborado pelos pesquisadores, com base nos dados da pesquisa de campo.

A primeira codificação focada deu origem a 48 códigos focados, total reduzido para 35 subcategorias, agrupadas em 12 categorias, que foram aglutinadas em cinco códigos axiais

Codificação axial: Trata as relações existentes entre as categorias e as subcategorias, feitas com base naquilo que apresentam em comum em termos de significados, assim como o impacto que causam umas nas outras. Assim como os códigos focados, receberam apenas um nome, como um construto (Quadro 3).

Quadro 3

Código focado $\rightarrow$ Código axial

\begin{tabular}{|l|l|l|}
\hline \multicolumn{2}{|l|}{ Código focado } & Código axial \\
\hline Subcategoria & Geral & \\
\hline Desafios & & Competência \\
\hline Foco & Gestão & \\
\hline Desempenho & & \\
\hline Processo decisório & & \\
\hline
\end{tabular}

Fonte: Elaborado pelos pesquisadores, com base nos dados da pesquisa de campo.

A forma como os passos seguidos na análise foram descritos até aqui pode dar ensejos a uma estruturação positivista. Entretanto, isto foi feito visando facilitar o entendimento do processo.

A partir deste ponto, a dinâmica da análise por meio da $G T$ mostra-se mais diferenciada dos outros métodos de análise de conteúdo, dado seu enfoque interpretativista, porém, principalmente, mais interacionista - ou seja, o que está por trás do código em si. 
$\checkmark$ Codificação teórica/elaboração de memos: Esta quarta fase do processo de análise sofreu um novo ajuste para este estudo, visto que o objetivo não era a construção de uma teoria substantiva.

A codificação teórica, fase em que as hipóteses quanto às relações encontradas nas codificações focada e axial são formuladas, foi realizada em conjunto com a elaboração de memos - notas sobre relações, hipóteses e potencial pré-teoria. Ambas, no entanto, com escopo totalmente interpretativista, consubstanciadas em aportes teóricos adicionais àqueles conteúdos que orientaram as primeiras análises.

$\checkmark$ Elaboração da primeira versão: Utilizada para a elaboração do modelo de relações, em que são articulados os códigos axiais, incluindo toda a conexão teórica.

$\checkmark$ Reflexão sobre o processo de pesquisa: Foi elaborada de forma a dar alinhamento ao processo efetivamente conduzido e aos achados, na forma em que foram analisados e interpretados - neste caso, passo destinado à análise de consistência do modelo de relações.

Não obstante, dentro do terceiro passo - codificação teórica/elaboração de memos, adaptados da forma como sugeridos por Charmaz (2006) - foi feita uma articulação da $G T$ com a análise semiótica peirceana, considerando o roteiro sugerido por Santaella (2002), o que se julgou necessário para dar conta das codificações à luz da semiótica, enquanto método de análise dos dados.

Julga-se fundamental abrir parênteses aqui para citar a visão de Buczynska-Garewicks (1983) sobre a semiótica peirceana ser tanto uma abordagem teórica quanto uma metodologia de análise e interpretação de dados. Expressando essa ideia, a autora vai além em sua definição de semiótica como uma "filosofia de interpretação (...) cuja noção de interpretação cria uma junção de semiótica e hermenêutica" (p. 27 - tradução feita pelo pesquisador), sendo a semiótica, em sua visão, inclusive, muito mais ampla que a hermenêutica, pois a riqueza e a profundidade taxonômica da semiótica peirceana são perfeitamente suficientes para permitir ilações dentro dos contextos simbólicos (MIGUEL, 2010).

Portanto, ao cabo da fase de codificação axial e em seguida a ela, concomitantemente à codificação teórica/elaboração de memos, utilizou-se a análise semiótica para entender os signos na relação entre seu objeto imediato e seu objetivo dinâmico - ou seja, o signo que se vê e o que ele representa, gerando três categorias essenciais: ícones, índices e símbolos, das quais outras categorias decorrem, conforme seja uma qualidade (quali-signo), algo existente (sin-signo) ou uma lei (legi-signo), como resume Santaella (2002).

Não obstante, corrobora-se totalmente a avaliação de Santaella (2002) quanto à complexidade na elaboração de uma análise semiótica, pois além da natureza subjetiva dos dados, independentemente do tipo a que pertencem, é imprescindível que se lance mão da aplicação de outras técnicas de análise a fim de torná-la assertiva, e isto se aplica a qualquer tipo de dado - textuais, auditivos e visuais.

\section{Análise de imagens e sons}

Com base nessa premissa, também as interpretações sobre o conteúdo das fotos e dos vídeos feitos pelo pesquisador seguem os preceitos das técnicas de análise pertinentes a esse tipo de dado, em consonância com o que aconselha Santaella (2002), recorrendo a referências no assunto, cujos textos organizados por Bauer e Gaskell (2008), em torno de um único livro, deram conta de orientar a análise quanto a essas técnicas específicas.

Assim, adotou-se a técnica de análise semiótica de imagens paradas, sugerida por Penn (2008), e a técnica de análise de imagens em movimento, sugerida por Rose (2008), incorporadas aos preceitos de interpretação semiótica sugeridos por Santaella (2002) e Chandler (2001). 
Seguindo o caminho de análise de imagens paradas sugerido por Penn (2008), em que o primeiro passo é a seleção das imagens que se quer analisar, assumiu-se que esse passo fora dado no momento em que a câmera do pesquisador registrou cada uma das imagens, como já explicado antes.

Em função da grande quantidade de fotos, estas foram agrupadas em clusters, assumindo um critério, inicialmente, baseado no conteúdo que elas expunham - seu conteúdo denotativo, conforme Penn (2008): textos, imagens de pessoas, de estruturas, de espaços específicos. Isto resultou em uma combinação entre o primeiro e segundo passos sugeridos pela autora, como uma adequação para este estudo, exclusivamente.

Em seguida, trabalhou-se cada uma das partes das fotos, ainda em seus clusters, procurando as particularidades, buscando entender a mente do pesquisador, segundo Penn (2008), seu conteúdo conotativo, entrando, então, no universo da significação, e o sistema de referências ao qual ele diz respeito.

Conforme Miguel (2010), Penn (2008) não define uma forma de apresentação da interpretação, deixando a critério do intérprete a escolha. É importante salientar que foram utilizadas as recomendações da autora até este ponto, exclusivamente, porquanto, a linha semiótica seguida por ela é semiológica saussuriana. Isto levou a uma nova adequação para efeito deste estudo, pois a partir desse ponto, seguiram-se as recomendações de Santaella (2002), a partir, também, das abordagens teóricas de base.

No tocante aos vídeos, procurou-se seguir as recomendações de Rose (2008), para quem "todo passo, no processo de análise de materiais audiovisuais, envolve transladar (grifo nosso). E cada translado implica em decisões e escolhas" (p. 343). O problema mencionado por ela, e que se pode constatar, é que tanto o que é considerado na análise quanto o que não é, tornam-se igualmente importantes, pois as escolhas referem-se ao critério de viabilidade.

O início do processo sugerido por Rose (2008) para a análise de vídeos é similar ao início do processo sugerido por Penn (2008) para a análise de fotos: a seleção daquilo que se quer analisar. Da mesma forma, este primeiro passo foi dado no momento em que os eventos eleitos como relevantes foram registrados com a filmadora, relevância esta baseada naquilo que se buscava como "prova" de compartilhamento do conhecimento tácito na organização pesquisada. Este foi o critério que guiou as escolhas para as fotos e para os vídeos, enquanto registros de um evento, no caso, as interações entre seus membros, o que é importante que esteja claro, segundo a autora (MIGUEL, 2013).

Da mesma forma que na análise das fotos, agruparam-se os vídeos em clusters, seguindo a mesma temática denotativa de seus conteúdos: textos, imagens de pessoas, de estruturas, de espaços específicos, embora a autora não use o termo denotação.

O passo seguinte, como sugere Rose (2008), correspondeu à transcrição dos elementos que seriam alvo da análise, escolhidos com base nos aportes teóricos envolvidos na pesquisa. Essa fase foi difícil e complexa, em função dos paradigmas que permeavam o estudo. Dessas escolhas, dependia a qualidade das análises e das interpretações, pois a partir desse momento, a interpretação passou a contar uma história sob o ponto de vista do pesquisador, exclusivamente, com todos os riscos que isto envolve, como alerta Santaella (2002), embora se possa acreditar que tais escolhas iniciaram-se no momento em que os registros foram criados.

A transcrição dos vídeos pode ser considerada, conforme Rose (2008), de natureza mais simples, seguindo tão somente um roteiro que envolveu (1) a codificação do ângulo da câmera (nível do close up - normal, médio, máximo), dando conta da existência da ênfase, e (2) a anotação sobre uma tomada única, dupla ou de grupo, registrando o número de pessoas envolvidas na tomada.

Dada a natureza e o objetivo dos registros, não foram necessárias, porque não existentes, considerações a respeito da intensidade da luz ou a utilização de som ensejando significados conotativos distintos e deliberados. 
No entanto, em uma nova adequação metodológica para este estudo, houve-se por bem apropriar-se das sugestões de Bauer (2008) para a análise de ruídos nas imagens em movimento registradas pelo pesquisador, seguidas por meio destes passos, visando o registro dos ruídos para a obtenção de "um traço material", segundo Bauer (2008, p. 367): (1) registro e transcrição do evento sonoro, (2) descrição dos ruídos existentes nos vídeos conforme suas dimensões quanto a ciclos, sonoridade e tipo, e (3) observação sobre as características específicas desses ruídos, quanto a serem produzidos por um determinado grupo social ou aos quais um determinado grupo social estaria exposto, ou os escutaria (MIGUEL, 2013).

Ao final dessas transcrições e similarmente ao processo de análise utilizado para as fotos, utilizou-se a taxonomia semiótica peirceana para interpretar esses dados, à luz do arcabouço teórico abordado inicialmente, bem como novos aportes que se fizeram necessários para complementar e/ou explicar as ilações feitas durante o processo de análise e interpretação.

Numa escolha própria para este estudo, utilizou-se, ainda, o método de análise de ruídos, para complementar e enriquecer a análise dos relatos à busca de entonações de voz, hesitações, embargos de fala, que denotassem algum significado especial para o entrevistado.

\section{A integração das relações por meio das comparações constantes}

Todo o esforço de análise baseou-se sempre no método de comparações constantes sugerido por Charmaz (2006), pois embora cada grupo de dados contemplasse a necessidade da utilização de técnicas específicas adicionais (Quadro 4), à exceção dos relatos, estas foram, ao longo do processo, mecanismos complementares de análise, de forma a garantir o critério de fidelidade deste trabalho sobre os aspectos simbólicos e semânticos.

Como todo o material visual e sonoro passou pela fase de transcrição em seu processo de análise, as transcrições podem ser analisadas como dados, podendo ser interpretados à luz do método da $G T$ por meio da técnica de comparações constantes, sem que, no entanto, precisassem passar pela fase de codificação inicial, sendo inseridos nos contextos dos códigos focados diretamente.

\section{Quadro 4}

\section{Síntese do caminho metodológico percorrido}

\begin{tabular}{|l|l|l|l|l|}
\hline \multicolumn{5}{|c|}{ Estratégia de Pesquisa: Estudo de Caso - Merriam (1988, 1998, 2002). } \\
\hline \multicolumn{1}{|c|}{$\begin{array}{l}\text { Tipo de } \\
\text { Dado }\end{array}$} & Meio de Coleta & $\begin{array}{l}\text { Instrumento } \\
\text { de Coleta }\end{array}$ & $\begin{array}{c}\text { Método e } \\
\text { Técnica de Análise }\end{array}$ & \multicolumn{1}{|c|}{ Autores } \\
\hline Relato & Entrevista & $\begin{array}{l}\text { Roteiro não } \\
\text { estruturado }\end{array}$ & $G T$ & $\begin{array}{l}\text { Charmaz (2006) } \\
\text { Santaella (2002) } \\
\text { Chandler (2001) }\end{array}$ \\
\hline $\begin{array}{l}\text { Imagens } \\
\text { paradas }\end{array}$ & $\begin{array}{l}\text { Observação } \\
\text { participativa }\end{array}$ & $\begin{array}{l}\text { Registro } \\
\text { fotográfico }\end{array}$ & $\begin{array}{l}\text { GT+ Análise Imagens } \\
\text { Paradas + Semiótica }\end{array}$ & $\begin{array}{l}\text { Charmaz (2006), } \\
\text { Penn (2008), } \\
\text { Santaella (2002) }\end{array}$ \\
\hline $\begin{array}{l}\text { Imagens em } \\
\text { movimento e } \\
\text { som }\end{array}$ & $\begin{array}{l}\text { Observação } \\
\text { participativa }\end{array}$ & $\begin{array}{l}\text { Registro } \\
\text { visual/sonoro }\end{array}$ & $\begin{array}{l}\text { Movimento e Som + } \\
\text { Semiótica }\end{array}$ & $\begin{array}{l}\text { Charmaz (2006), } \\
\text { Rose (2008), Bauer } \\
\text { (2008), Santella } \\
\text { (2002), }\end{array}$ \\
\hline
\end{tabular}

Fonte: Elaborado pelos pesquisadores, com base nos dados da pesquisa de campo. 
À medida que novos aportes teóricos se fizeram necessários, foram incorporados no contexto ao qual pertenciam, dentro da análise e da interpretação dos dados.

Assim, cada uma das fases seguiu a mesma sequência metodológica da $G T$, integrada às técnicas metodológicas que lhes eram pertinentes dentro de suas especificidades, gerando quadro parciais de relações, integrados ao final.

O fluxo do desenho desta pesquisa, considerando todas as etapas, é apresentado resumidamente na Figura 2.

Figura 2

\section{Fluxo do desenho da pesquisa}

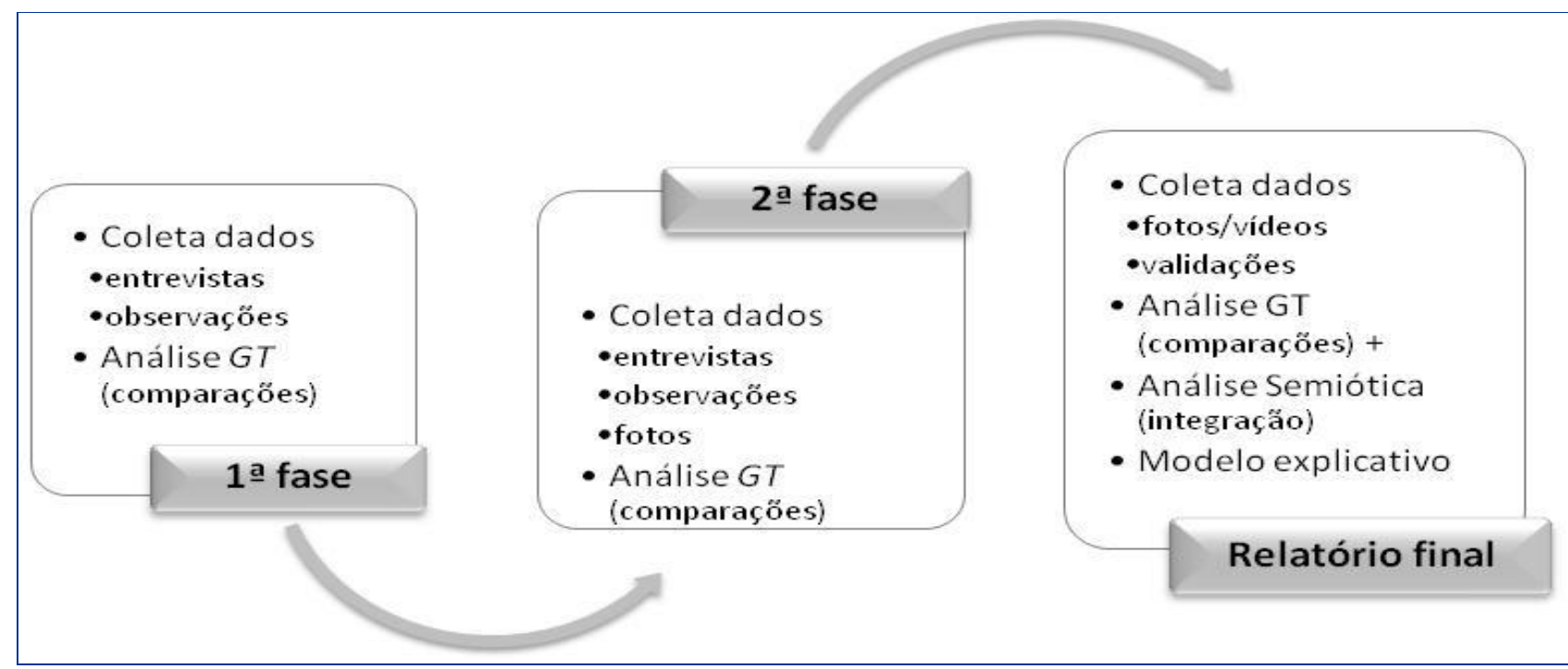

Fonte: Elaborado pelos pesquisadores, com base nos dados da pesquisa de campo.

\section{Considerações Finais}

Este artigo apresentou um caso prático em que a combinação de técnicas de análise dos dados colhidos durante o processo de pesquisa pode contemplar não somente a diversidade de dados coletados, mas, principalmente a riqueza de significados que tais dados continham, dentro do paradigma interacionista simbólico.

A fase de análise de dados dentro de um projeto de pesquisa qualitativa é de crucial importância para que se possa capturar toda a essência e riqueza das várias facetas existentes em tudo aquilo que se colheu no campo. Não obstante, a escolha dos métodos de análise deve dar conta de analisar todo o tipo de dado coletado, combinando técnicas de análise que estejam alinhadas entre si dentro do paradigma predominante no trabalho científico, de forma a produzir resultados que se coadunem com a riqueza de significados existentes nas informações colhidas no campo, sob a ótica dos atores envolvidos na pesquisa, os indivíduos entrevistados, sem a preocupação de buscar uma relação de causa e efeito, mas, sim, puramente interpretativista.

Por esta razão, o escopo interacionista que orienta este trabalho direcionou o olhar do pesquisador quanto à obtenção de dados e à forma de analisá-los, dentro do mesmo arcabouço epistemológico interpretativista, inclusive e, principalmente, quanto à necessidade de inclusão de novos conteúdos teóricos que dessem conta de explicar os fenômenos observados. 
Não é uma tarefa fácil, pois a plêiade de visões teóricas a respeito de um mesmo conceito pode eventualmente confundir o pesquisador, uma vez que na ânsia de embasar sua análise, nem sempre conhece os meandros da linha que cada autor teórico de base segue, qual seja dogmática, cética, positivista, interpretativista, pragmática, entre outras. Algumas dessas linhas podem até conversar entre si, mesmo que de forma tênue, mas outras, são contundentemente contrárias, como, por exemplo, o intelectualismo e o pragmatismo. Como exemplo disto, Santaella (1986) nos expõe a preocupação de Peirce em redefinir sua linha epistomologica como pragmaticismo. Do contrário, como um pragmatisma, conflitaria com a visão intelectualista da qual comungava.

Embora pareça preciosismo, o cuidado com a consistência epistemológica dá conta de como o pesquisador valida seus achados, pela forma como apresenta a criação da realidade de seu objeto de estudo, ou seja, o conhecimento criado.

Espera-se que este caso prático possa servir de exemplo e base para futuros estudos que necessitem de uma articulação metodológica mais complexa, de forma a trazer à luz a relevância dos significados existentes na pesquisa de campo realizada.

\section{Referências}

BANDEIRA-DE-MELLO, R.; CUNHA, C. J. C. A. Grounded theory. In: GODOI, C. K.; BANDEIRA-DE-MELLO, R.; SILVA; A. B. (Orgs.). Pesquisa qualitativa em estudos organizacionais: paradigmas, estratégias e métodos. São Paulo: Editora Saraiva, 2006.

BAUER, M. W. Análise de ruído e música como dados sociais. In: ; GASKELl, G. (Eds.). Pesquisa qualitativa com texto, imagem e som. Um manual prático. Petrópolis, Vozes, 2008, 365-389 p.

BUCZYNSKA-GAREWICKS, H. Sign and dialogue. American Journal of Semiotics, v. 2, n.1-2, p. 27-43, 1983.

CAMPOS, C. J. C. Método de análise de conteúdo: ferramenta para a análise de dados qualitativos no campo da saúde. Revista Brasileira de Enfermagem, Brasília (DF), v. 57, n. 5, p. 611-4, set/out. 2004.

CHANDLER, D. Semiotics for beginners. Disponível em:

http://www.aber.ac.uk/media/Documents/S4B/semiotic.html, 2001. Acesso em 10 outubro 2009.

Semiotics: the basics. 2. ed. New York: Routledge, 2007.

CHARMAZ, K. Constructing grounded theory. A practical guide through qualitative analysis. London: Sage Publications, 2006.

GASKELL, G. Entrevistas individuais e grupais. In: BAUER, M. W.; GASKELL, G. (Eds.). Pesquisa qualitativa com texto, imagem e som. Um manual prático. Petrópolis, Vozes, 2008, 64-89 p.

GODOY, A. S. Estudo de caso qualitativo. In: GODOI, C. K.; BANDEIRA-DE-MELLO, R.; SILVA; A. B. (Orgs.). Pesquisa qualitativa em estudos organizacionais: paradigmas, estratégias e métodos. São Paulo: Saraiva, 2006.

GOULDING, C. Grounded theory: a practical guide for management, business and market researchers. London: Sage Publications, 2002.

LOIZOS, P. Vídeo, filme e fotografias como documentos de pesquisa. In: BAUER, M. W.; GASKELL, G. (Eds.) Pesquisa qualitativa com texto, imagem e som: um manual prático. Petrópolis: Vozes, 2002, 137-155 p.

MERRIAM, S. B. Qualitative research and case study applications in education. 1. ed. San Francisco: Jossey-Bass, 1988 . 
Qualitative research and case study applications in education. 2. ed. San Francisco: Jossey-Bass, 1998.

Qualitative research in practice. Examples for discussion and analysis. San Francisco: Jossey-Bass, 2002.

MIGUEL, L. A. P. A semiótica do compartilhamento do conhecimento tácito em uma organização cooperativa: uma perspectiva integradora. 2010. Tese (Doutorado em Administração de Empresas) - Universidade Presbiteriana Mackenzie, São Paulo, 2010.

. A semiótica a serviço da inovação: o conhecimento tácito e os signos. São Paulo: Editora Mackenzie, 2013.

PEIRCE, C. S. Semiótica. São Paulo: Perspectiva, [1931-1958] 2000.

PENN, G. Análise semiótica de imagens paradas. In: BAUER, M. W.; GASKELL, G. (Eds.). Pesquisa qualitativa com texto, imagem e som. Um manual prático. Petrópolis, Vozes, 2008, 319-342 p.

POLANYI, M. Personal knowledge. Chicago: The University of Chicago Press, 1962.

The tacit dimension. London: Routledge \& Kegan Paul, 1966.

ROSE, D. Análise de imagens em movimento. In: BAUER, M.W.; GASKELL, G. (Eds.). Pesquisa qualitativa com texto, imagem e som. Um manual prático. Petrópolis, Vozes, 2008, 343-389 p.

SANTAELLA, L. O que é semiótica. 2. ed. São Paulo: Brasiliense, 1986.

Semiótica aplicada. São Paulo: Thomson, 2002.

SILVERMAN, D. Doing qualitative research: a practical handbook. London: Sage, 2000.

Interpreting qualitative data: methods for analyzing talk, text, and interaction. 2. ed. London: Thousand Oaks, California: Sage Publications, 2001. 